\title{
Fast, copper-free click chemistry: a convenient solid-phase approach to oligonucleotide conjugation $\dagger$
}

\author{
Ishwar Singh, ${ }^{a}$ Joseph S. Vyle ${ }^{b}$ and Frances Heaney ${ }^{* a}$ \\ Received (in Cambridge, UK) 2nd March 2009, Accepted 9th April 2009 \\ First published as an Advance Article on the web 22nd April 2009 \\ DOI: $10.1039 / b 904185 k$
}

Solid-phase oligonucleotide conjugation by nitrile oxide-alkyne click cycloaddition chemistry has been successfully demonstrated; the reaction, compatible with all nucleobases, requires no metal catalyst and proceeds under physiological conditions.

The availability of reliable, robust and efficient chemistry for the provision of oligonucleotide conjugates is central to much of contemporary genomic research and to studies directed toward nucleic acid therapies. Whilst both solution- and solid-phase syntheses of such conjugates have been demonstrated, the latter has many advantages, particularly in terms of product purification. Generally, to encourage effective coupling, the syntheses are conducted with large excesses of the conjugating group and in the solid-phase approach excess reagents, together with undesired side products, can simply be removed by washing. To this end we wish to report an effective strategy for chemical modification of DNA by copper-free, click cycloaddition chemistry in the solid-phase.

Seminal insights into the application of the HuisgenMeldal-Sharpless azide-alkyne cycloaddition, considered the prototype of click chemistry, ${ }^{1}$ for solution-phase oligonucleotide bioconjugation have been provided by a number of laboratories. ${ }^{2}$ However, reports on solid-supported oligonucleotide modification by $\mathrm{Cu}(\mathrm{I})$ promoted azide-alkyne click reactions are limited ${ }^{2 b, c}$ and some proceed only with microwave activation. ${ }^{2 g}$ Despite the successes of these reactions a number of concerns persist. Apprehension exists over the handling of potentially toxic and explosive organic azides ${ }^{3}$ and whilst in situ dipole generation begins to address this problem, ${ }^{4}$ the requirement for a $\mathrm{Cu}(\mathrm{I})$ catalyst brings its own technical difficulties. ${ }^{5}$ To help deter the DNA degrading redox chemistry of $\mathrm{Cu}(\mathrm{I})$ the reaction must be conducted under air-free conditions ${ }^{2 f}$ in the presence of a tris-triazolylamine $\mathrm{Cu}(\mathrm{I})$ ligand. ${ }^{2 d, 6}$ Finally, extensive washing is recommended to ensure quantitative removal of the copper salt and the ligand during the reaction work-up. $^{2 h}$ Against this background a fast, copper-free, alternative to the azide-alkyne click reaction is highly desirable. To date, no solid-phase alternative to the $\mathrm{Cu}(\mathrm{I})$ promoted reaction has been reported and only two solution-phase approaches

\footnotetext{
${ }^{a}$ Department of Chemistry, National University of Ireland, Maynooth, Co. Kildare, Republic of Ireland. E-mail: mary.f.heaney@nuim.ie; Fax: + 353 1708 3815; Tel: + 35317083802

${ }^{b}$ School of Chemistry and Chemical Engineering, The Queen's University of Belfast, David Keir Building, Stranmillis Road, Belfast, Northern Ireland, UK. E-mail: j.vyle@qub.ac.uk;

Fax: + 44 (0)289097 652; Tel: + 44 (0)2890975485

$\dagger$ Electronic supplementary information (ESI) available: Experimental procedures, NMR spectra, fluorescence spectra, melting temperature determinations, MALDI-TOF MS data and HPLC data. See DOI: $10.1039 / \mathrm{b} 904185 \mathrm{k}$
}

toward this goal have appeared in the literature. These too have their limitations. First, a ruthenium-catalysed azidealkyne "fusion" reaction proceeds best in organic solvents with yields and regioselectivity compromised in protic solvents. ${ }^{7}$ Second, Bertozzi et al.'s strain promoted azide-alkyne reaction is not regiospecific. And third, the required strained cyclic alkynes are available only following long synthetic sequences. ${ }^{8}$ Thus, a void exists in the field of chemical biology for a fast, reliable, copper-free, solid-phase oligonucleotide conjugation strategy which will proceed under physiological conditions.

We considered it unlikely that azides should be the only family of Huisgen classified 1,3-dipoles ${ }^{9}$ with potential to act as click cycloaddition partners and that the isoxazole generating nitrile oxide-alkyne reaction has many attractions. Firstly, the ease of dipole formation. ${ }^{10}$ Secondly, cycloaddition of nitrile oxides to alkynes is calculated to be $\sim 6 \mathrm{kcal} \mathrm{mol}^{-1}$ lower than that for similar azides, implying acceptable reaction rates at room temperature. ${ }^{11}$ Thirdly, reactions of nitrile oxides with monosubstituted alkynes are regioselective for formation of 3,5-disubstituted adducts. ${ }^{12}$ Finally, the isoxazole ring, present in many bioactive compounds, has many possible modes of action with biological molecules. ${ }^{13}$

The hypothesis that nitrile oxide-alkyne click chemistry offers a reliable tool to chemically modify oligonucleotides was initially tested in solution on the nucleoside $\mathbf{1}$. Chloramine-T was selected as the dipole generating agent; ${ }^{10 b}$ its use in antibody-catalysed 1,3-dipolar cycloaddition reactions ${ }^{14}$ and in the preparation of ${ }^{125}$ I-labelled oligonucleotides ${ }^{15}$ suggests, with judicious choice of reacting concentration, compatibility with biological systems. Treatment of 1 with benzonitrile oxide, generated in situ from benzaldehyde oxime, and chloramine-T afforded isoxazole-modified thymidine $\mathbf{2}$, eqn (1). A singlet resonance at $6.59 \mathrm{ppm}$ in the ${ }^{1} \mathrm{H}$ NMR spectrum, diagnostic for the $4-\mathrm{H}$ proton, confirms the regiospecificity of the reaction.

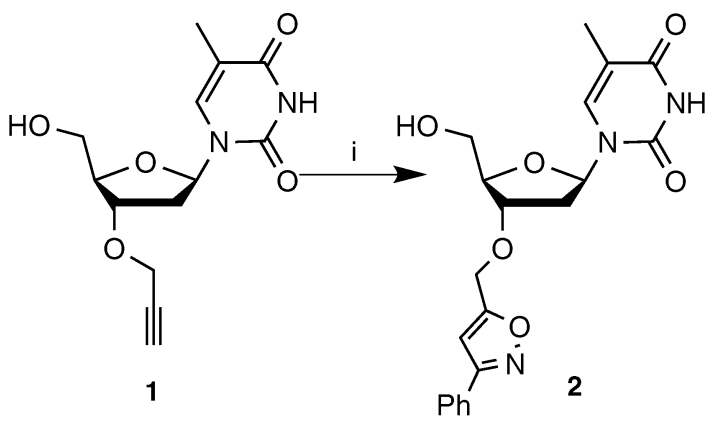

i. Chloramine-T, EtOH, aq. $\mathrm{NaHCO}_{3}(4 \%)$, rt, $\mathrm{PhCH}=\mathrm{NOH}, 12 \mathrm{~h}$ 

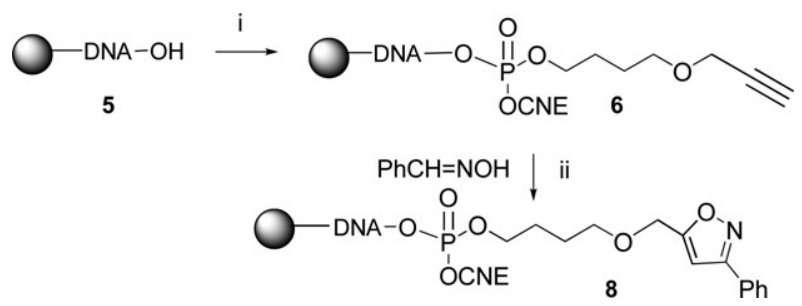

Scheme 1 Solid-phase synthesis of isoxazole-ligated oligonucleotides. (a) DNA $=$ thymidine, (b) DNA $=\mathrm{T}_{10}$, (c) DNA $=5^{\prime}$-TCGCACACACGC-3 ${ }^{\prime}$. (i) 4, BMT, $\mathrm{CH}_{3} \mathrm{CN}$, rt, $30 \mathrm{~min}$ then $\mathrm{I}_{2}(0.1 \mathrm{M}) \mathrm{THF}-$ pyridine- $\mathrm{H}_{2} \mathrm{O}$; (ii) chloramine-T, aq $\mathrm{NaHCO}_{3}$ (4\%), EtOH, rt (a) $30 \min$ (b) $30 \min$ (c) $10 \mathrm{~min}$.

The inherent advantages of the solid-phase approach to oligonucleotide conjugation, viz less intensive purification, lead to demonstration of the resin-supported nitrile oxide click reaction. Commercially available $500 \AA$ CPG-succinyl nucleoside support was selected. The phosphoramidite alkyne $\mathbf{4}$ was synthesised, eqn (2), and attached directly to the $5^{\prime}$-position of CPG-loaded thymidine 5a, Scheme 1. Reversed-phase HPLC analysis of a sample of 7a, obtained following the deprotection-cleavage protocol, indicated quantitative conversion to the thymidine-alkyne $\mathbf{6 a}$, Fig. 1 . The reactivity of the support-bound alkyne $\mathbf{6 a}$ in nitrile oxide click cycloaddition chemistry was tested by exposing it to benzaldehyde oxime and chloramine-T in ethanolic $\mathrm{NaHCO}_{3}$, Scheme 1 . Following deprotection and cleavage, near-quantitative conversion to the isoxazole-nucleotide conjugate $9 \mathbf{a}$ was evidenced by HPLC analysis. MALDI-TOF-MS of 7a and $\mathbf{9 a}$ confirmed the structural integrity of both products.

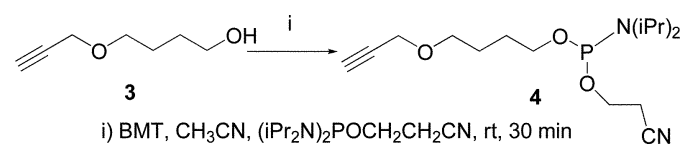

A parallel reaction sequence with CPG-supported decathymidylate, $\mathbf{5 b}$, confirmed compatibility with longer chain oligonucleotides and the isoxazole-ligated decamer $\mathbf{8 b}$ formed from the resin-bound DNA-alkyne $\mathbf{6 b}$. Quantitative yields for the coupling and the click reactions were evident from HPLC analysis, Fig. 2a,b. MALDI-TOF-MS data confirmed the structure of the alkyne $\mathbf{7 b}$ and the isoxazole-ligated- $\mathrm{T}_{10}, \mathbf{9 b}$.

A control experiment verifies the chemoselectivity of the reaction, and CPG-supported decathymidylate 5b was returned unchanged following experimentation under the conditions of the nitrile oxide-alkyne click reaction, thus confirming that the nitrile oxide reacts only with the alkyne.

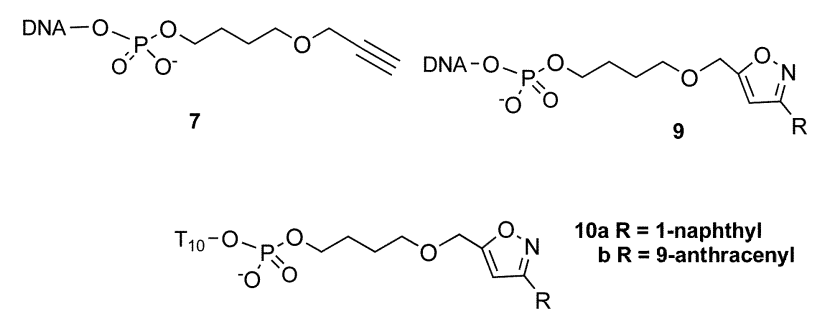

Fig. 1 Structures of modified oligonucleotides following cleavage from the support and deprotection. (a) DNA = thymidine, (b) DNA $=\mathrm{T}_{10}$, (c) DNA $=5^{\prime}$-TCGCACACACGC-3'

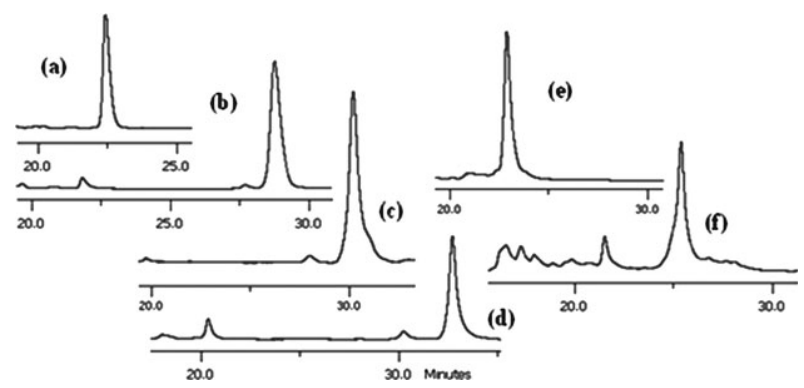

Fig. 2 Reversed-phase HPLC analysis of crude reaction products (UV absorbance at $260 \mathrm{~nm} v s$. time). (a) Linear oligonucleotide (7b), (b) isoxazole-oligonucleotide (9b), (c) isoxazole-oligonucleotide (10a), (d) isoxazole-oligonucleotide (10b), (e) linear oligonucleotide (7c), (f) isoxazole-oligonucleotide (9c).

A fluorogenic version of the reaction confirms its efficacy for biolabelling applications. Since polycyclic aromatic compounds are known base surrogates for DNA ${ }^{16}$ and since anthracenes intercalate DNA strands and their fluorescent properties are tunable, ${ }^{17}$ in situ generated naphthalene 1-nitrile oxide and anthracene 9-nitrile oxide were selected as click partners for CPG- $\mathrm{T}_{10}$-alkyne $\mathbf{6 b}$. Employing the chloramine-T methodology, quantitative conversion to the clicked products was judged from HPLC analysis on 10a,b, obtained after deprotection-cleavage, Fig. 2c,d. MALDI-TOF-MS data confirmed the structures of $\mathbf{1 0 a}, \mathbf{b}$. The fluorescence spectrum of the naphthalene bearing single stranded oligonucleotide 10a showed a strong fluorescence with an emission maximum at $376 \mathrm{~nm}$ and an excitation at $310 \mathrm{~nm}$ whilst its anthracene analogue 10b showed an emission maximum at $429 \mathrm{~nm}$ and an excitation at $350 \mathrm{~nm}$.

To have real value for oligonucleotide bioconjugation the solid-phase click reaction must be compatible with nucleobases more susceptible to mutagenic modification, i.e. cytosine, guanine and adenine. Thus, the resin-bound dodecamer $\mathbf{6 c}$ was prepared. HPLC analysis, Fig. 2e, and MALDI-TOF-MS characterisation of $\mathbf{7 c}$ confirmed successful attachment of the alkyne. However, the hetero-oligonucleotide was sensitive to the conditions used to effect the click reaction; optimal conditions involved reaction of $\mathbf{6 c}(0.2 \mu \mathrm{M})$ in ethanolic aqueous $\mathrm{NaHCO}_{3}(1: 2)$ with chloramine- $\mathrm{T}(114 \mathrm{mg})$ and oxime $(31 \mathrm{mg})$ for 10 minutes at room temperature. HPLC analysis showed good conversion to the isoxazole-modified DNA, 9c, Fig. 2f and the MALDI-TOF-MS unambiguously confirmed the expected mass of the isoxazole-ligated product 9c. The thermal consequences of isoxazole introduction were evaluated by UV melting experiments. The unmodified oligonucleotide 11, 5'-TCGCACACACGC-3' ${ }^{\prime}$, and the click functionalized derivative $9 \mathbf{c}$ were hybridised with the complementary strand 12, 5'-GCGTGTGTGCGA-3'. The duplex 9c12 shows a $T_{\mathrm{m}}$ value of $69.7 \pm 0.7{ }^{\circ} \mathrm{C}$ whilst the reference duplex 11.12 shows a $T_{\mathrm{m}}$ value of $67.0 \pm 0.9$. Thus, it is clear that the isoxazole moiety enhances DNA duplex stability.

In conclusion, a solid-phase nitrile oxide-alkyne click reaction has been used to form isoxazole conjugated oligonucleotides. The procedure, which has potential for application in bioconjugation, polymer and materials science and drug discovery, is selective, convenient and fast. It occurs under 
atmospheric conditions, in aqueous solvents, within minutes not hours, and is high yielding and highly regioselective. Importantly, it does not require a $\mathrm{Cu}(\mathrm{I})$ catalyst nor an oxygen-free environment. Thus, the solid-phase nitrile oxide-alkyne reaction offers a valuable click alternative to azide-alkyne chemistry for applications in oligonucleotide bioconjugation. $^{2}$

We thank C. Batchelor, NUI Maynooth, for assistance with MALDI-TOF mass spectral measurements. Financial support from the Science Foundation of Ireland (Programme code 05/PICA/B838) is gratefully acknowledged.

\section{Notes and references}

1 (a) H. C. Kolb, M. G. Finn and K. B. Sharpless, Angew. Chem., Int. Ed., 2001, 40, 2004-2021; (b) C. W. Tornoe, C. Christensen and M. Meldal, J. Org. Chem., 2002, 67, 3057-3064.

2 Selected examples include: (a) A. Salic and T. J. Mitchison, Proc. Natl. Acad. Sci. U. S. A., 2008, 105, 2415-2420; (b) F. Seela and V. R. Sirivolu, Helv. Chim. Acta, 2007, 90, 535-552; (c) P. M. E. Gramlich, S. Warncke, J. Gierlich and T. Carell, Angew. Chem., Int. Ed., 2008, 47, 3442-3444; (d) R. Kumar, A. El-Sagheer, J. Tumpane, P. Lincoln, L. M. Wilhelmsson and T. Brown, J. Am. Chem. Soc., 2007, 129, 6859-6864; (e) T. S. Seo, Z. M. Li, H. Ruparel and J. Y. Ju, J. Org. Chem., 2003, 68, 609-612; $(f)$ A. V. Ustinov and V. A. Korshun, Russ. Chem. Bull., 2006, 55, 1268-1274; ( $g$ ) C. Bouillon, A. Meyer, S. Vidal, A. Jochum, Y. Chevolot, J. P. Cloarec, J. P. Praly, J. J. Vasseur and F. Morvan, J. Org. Chem., 2006, 71, 4700-4702; (h) A. Kiviniemi, P. Virta and H. Loennberg, Bioconjugate Chem., 2008, 19, 1726-1734.

3 (a) E. F. V. Scriven and K. Turnbull, Chem. Rev., 1988, 88, 297-368; (b) J. P. Hagenbuch, Chimia, 2003, 57, 773-776.

4 P. Appukkuttan, W. Dehaen, V. V. Fokin and E. Van der Eycken, Org. Lett., 2004, 6, 4223-4225.

5 V. V. Fokin, ACS Chem. Biol., 2007, 2, 775-778.
6 T. R. Chan, R. Hilgraf, K. B. Sharpless and V. V. Fokin, Org. Lett., 2004, 6, 2853-2855.

7 (a) L. Zhang, X. G. Chen, P. Xue, H. H. Y. Sun, I. D. Williams, K. B. Sharpless, V. V. Fokin and G. C. Jia, J. Am. Chem. Soc., 2005, 127, 15998-15999; (b) D. Imperio, T. Pirali, U. Galli, F. Pagliai, L. Cafici, P. L. Canonico, G. Sorba, A. A. Genazzani and G. C. Tron, Bioorg. Med. Chem., 2007, 15, 6748-6757; (c) S. Grecian and V. V. Fokin, Angew. Chem., Int. Ed., 2008, 47, 8285-8287.

8 J. M. Baskin, J. A. Prescher, S. T. Laughlin, N. J. Agard, P. V. Chang, I. A. Miller, A. Lo, J. A. Codelli and C. R. Bertozzi, Proc. Natl. Acad. Sci. U. S. A., 2007, 104, $16793-16797$.

9 R. Huisgen, in 1,3-Dipolar Cycloaddition, ed. A. Padwa, Wiley, New York, 1984, vol. 1, pp. 1-176.

10 (a) Nitrile Oxides, Nitrones and Nitronates in Organic Synthesis: Novel Strategies in Synthesis, ed. H. Feuer, Wiley, New Jersey, 2nd edn, 2008; (b) A. Hassner and K. M. L. Rai, Synthesis, 1989, 57-59.

11 F. Himo, T. Lovell, R. Hilgraf, V. V. Rostovtsev, L. Noodleman, K. B. Sharpless and V. V. Fokin, J. Am. Chem. Soc., 2005, 127, 210-216.

12 E. Coutouli-Argyropoulou, P. Lianis, M. Mitakou, A. Giannoulis and J. Nowak, Tetrahedron, 2006, 62, 1494-1501.

13 B. L. Deng, T. L. Hartman, R. W. Buckheit, C. Pannecouque, E. De Clercq and M. Cushman, J. Med. Chem., 2006, 49, 5316-5323; T. M. V. D. Pinho e Melo, Curr. Org. Chem., 2005, 9, 925-958.

14 J. D. Toker, P. Wentworth, Y. F. Hu, K. N. Houk and K. D. Janda, J. Am. Chem. Soc., 2000, 122, 3244-3245.

15 M. W. Reed, I. G. Panyutin, D. Hamlin, D. D. Lucas and D. S. Wilbur, Bioconjugate Chem., 1997, 8, 238-243.

16 I. Singh, W. Hecker, A. K. Prasad, V. S. Parmar and O. Seitz, Chem. Commun., 2002, 500-501.

17 N. K. Modukuru, K. J. Snow, B. S. Perrin, A. Bhambhani, M. Duff and C. V Kumar, J. Photochem. Photobiol., A, 2006, 177, 43-54; M. D. Mosher, N. R. Natale and A. Vij, Acta Crystallogr., Sect. C: Cryst. Struct. Commun., 1996, 52, 2513-2515. 